\title{
Microwave Sintering of Ni-Based Bulk Metallic Glass Matrix Composite in a Single-Mode Applicator
}

\author{
Song $\mathrm{Li}^{1, *}$, Guoqiang $\mathrm{Xie}^{1}$, Dmitri V. Louzguine-Luzgin ${ }^{1,2}$, Ziping $\mathrm{Cao}^{3}$, \\ Noboru Yoshikawa ${ }^{3}$, Motoyasu Sato ${ }^{4}$ and Akihisa Inoue ${ }^{1,2}$ \\ ${ }^{1}$ Institute for Materials Research, Tohoku University, Sendai 980-8577, Japan \\ ${ }^{2}$ WPI Advanced Institute for Materials Research, Tohoku University, Sendai 980-8577, Japan \\ ${ }^{3}$ Graduate School of Environmental Studies, Tohoku University, Sendai 980-8577, Japan \\ ${ }^{4}$ National Institute for Fusion Science, Toki 509-5292, Japan
}

Microwave (MW) heating and sintering of Ni-based bulk metallic glass matrix composite, consisting of gas-atomized $\mathrm{Ni}_{52.5} \mathrm{Zr}_{15} \mathrm{Nb}_{10} \mathrm{Ti}_{15} \mathrm{Pt}_{7.5}$ glassy alloy and tin powders, was performed without external pressure by using a single-mode applicator. These powders could be heated well in the magnetic field maximum, but not heated enough in the electric field maximum. A bulk sintered body with the retention of the amorphous phase was obtained below $783 \mathrm{~K}$ in an inert atmosphere. The addition of Sn particles promoted the densification of the sintered $\mathrm{Ni}_{52.5} \mathrm{Zr}_{15} \mathrm{Nb}_{10} \mathrm{Ti}_{15} \mathrm{Pt}_{7.5}$ glassy specimen. The results suggest that the MW sintering of metallic glasses offers a flexibility of fabricating bulk metallic glasses and metallic glass matrix composites. [doi:10.2320/matertrans.MRA2008603]
[

(Received January 30, 2008; Accepted September 3, 2008; Published October 22, 2008)

Keywords: microwave sintering, metallic glassy powders, composite, E- and H-field

\section{Introduction}

Metallic glassy alloys with a structure having no longrange order have attained extensive attention as promising engineering materials due to their superior physical and chemical properties compared to their crystalline counterparts. ${ }^{1-3)}$ Although rapid solidification and casting techniques have been utilized to fabricate a variety of metallic glasses, their glass-forming ability is still limited which does not allow to produce industrial-size samples. Metallic glasses exhibit viscous flow in the supercooled liquid region between the glass transition temperature $T_{\mathrm{g}}$ and onset temperature of crystallization $T_{\mathrm{x}}$. Using this property consolidation of metallic glassy powders, which can be obtained via mechanical alloying or gas atomization methods, can be used for the production of metallic glassy alloys with large dimensions. Intensive efforts have been made for obtaining dense metallic glasses in a bulk form by applying extrusion and sintering techniques for metallic glassy powders. ${ }^{4-7)}$

Microwave (MW) radiation sintering is considered as an attractive method for processing metallic materials since it was first reported that particulate metals can be heated rapidly in MW field. ${ }^{8)}$ Compared with conventional sintering, MW radiation can provide more efficient and rapid heating and sintering because it is a volumetric heating involving conversion of electromagnetic energy into thermal energy, which is instantaneous, rapid and efficient. ${ }^{9,10)}$ It has been shown recently that some metals in the form of powder can absorb MW at room temperature, be heated efficiently and rapidly, and be sintered at least as quick as or faster than upon conventional heating, ${ }^{11-14)}$ though bulk metals cannot be heated by MW since they are opaque to MW and are good reflectors. Recently microwave radiation was successfully applied to heat metallic glassy powders ${ }^{15}$ ) due to it can provide some advantages over conventional heating such as direct volumetric heating, substantial energy savings,

*Corresponding author, E-mail: lisong@imr.tohoku.ac.jp reduction in the processing time and lower environmental hazard. Besides, MW sintering is deemed to induce decrystallization in some materials. ${ }^{16,17)}$ Thus MW sintering of metallic glasses is a promising technique for heat treating metallic powders.

In the present work, following our recent investigations ${ }^{15)}$ we explored the application of microwave radiation as the heating source for processing a mixture of $\mathrm{Ni}_{52.5} \mathrm{Zr}_{15^{-}}$ $\mathrm{Nb}_{10} \mathrm{Ti}_{15} \mathrm{Pt}_{7.5}$ metallic glassy alloy powders ${ }^{18)}$ and $\mathrm{Sn}$ powders in a separated electric (E-) and magnetic ( $\mathrm{H}-)$ fields using a single mode $2.45 \mathrm{GHz} \mathrm{MW}$ applicator, and investigated the influence of MW heating on the microstructure and properties of Ni-based metallic glass. The bulk body was achieved by sintering this mixture to a temperature close to $T_{\mathrm{g}}$, and less than $T_{\mathrm{x}}$. Sn particles with low melting point $(505 \mathrm{~K})$ can improve the quality of the sintered sample by transient liquid phase.

\section{Experimental Procedure}

$\mathrm{Ni}_{52.5} \mathrm{Zr}_{15} \mathrm{Nb}_{10} \mathrm{Ti}_{15} \mathrm{Pt}_{7.5}$ metallic glassy alloy powders were fabricated by a high pressure gas atomization method. The powders with the size below $63 \mu \mathrm{m}$ were used in the sequent sintering experiment. The details of the preparation have been shown in the previous paper. ${ }^{19)}$ Mixtures of $\mathrm{Ni}_{52.5} \mathrm{Zr}_{15} \mathrm{Nb}_{10^{-}}$ $\mathrm{Ti}_{15} \mathrm{Pt}_{7.5}$ metallic glassy alloy powders and $\mathrm{Sn}$ powders with an average size of $45 \mu \mathrm{m}$ of a volume ratio of $9: 1$ were prepared by powder mixing in a mixer. The theoretical density $\left(\rho_{0}\right)$ of the mixture is $8.350 \mathrm{~g} / \mathrm{cm}^{3}$. The volume ratio of the components was calculated according to their theoretical densities and qualities. A single-mode MW applicator (Nikoha MKN-152-359, max $1.5 \mathrm{~kW}$, Yokohama, Japan) was used for heating and sintering these blends. The powder specimens were enclosed in a holder made of silica glass with the dimensions of $5 \mathrm{~mm}$ in diameter and $7 \mathrm{~mm}$ in height. The adiabatic material like Kaowool blanket was placed around the specimen. These powders were placed inside two different locations in the wave guide applicator, the maximum E-field 


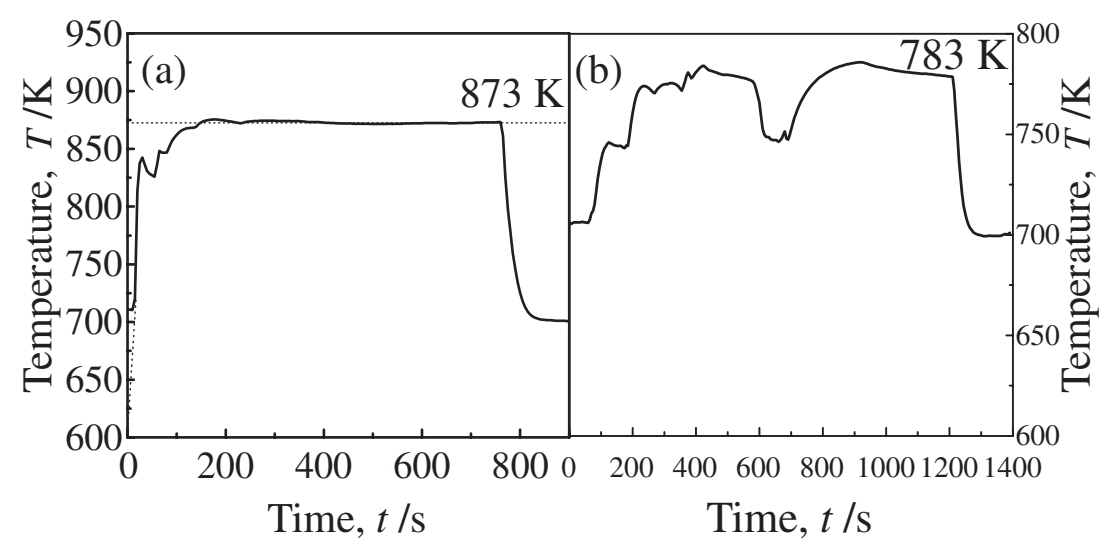

Fig. 1 (a) Heating curves of Ni-based metallic glass matrix composite containing 10 vol\% Sn heated in H-field up to $873 \mathrm{~K}$. (b) Heating curves of Ni-based metallic glass matrix composite containing 10 vol\% Sn heated in $\mathrm{H}$-field up to $783 \mathrm{~K}$. The initial temperature rise was not detected.

area where the $\mathrm{H}$-field is minimum, and the maximum $\mathrm{H}$-field area where the E-field is minimum, respectively. However, in E-field no noticeable response was seen, only in $\mathrm{H}$-field these powders could be heated by MW energy absorption up to appointed temperatures $(783,813,843$ and $873 \mathrm{~K})$ and held for about $600 \mathrm{~s}$. The details of the experimental procedure as well as computer simulations indicating $\mathrm{E}$ and $\mathrm{H}$ field separation can be found in a recent work. ${ }^{13)}$

Temperature measurement of the MW-heating specimens was performed with an optical method (PhotoriX system, Luxtron, Santa Clara, CA, USA), using a sapphire rod for the light guide. In this method, it is not possible to measure the specimen temperature below $623 \mathrm{~K}$. The adjustment of the temperature was done by controlling the three stubs to minimize the reflected power $\left(P_{\mathrm{r}}\right)$, while the input power $\left(P_{\mathrm{f}}\right)$ was kept constant. All experiments were carried out in a flowing nitrogen gas to avoid oxidation of metallic samples at high temperature.

The structures of the sintered specimens were examined by $\mathrm{X}$-ray diffraction (XRD) and scanning electron microscopy (SEM). The thermal stability was monitored by differential scanning calorimetry (DSC) at a heating rate of $40 \mathrm{~K} / \mathrm{min}$. The sintered density $\rho$ was estimated by dimensional measurements. Mechanical behaviors were examined under uniaxial compressive deformation mode at ambient temperature by an Instron testing machine with a constant strain rate of $5 \times 10^{-4} \mathrm{~s}^{-1}$.

\section{Results and Discussion}

A mixture of $\mathrm{Ni}_{52.5} \mathrm{Zr}_{15} \mathrm{Nb}_{10} \mathrm{Ti}_{15} \mathrm{Pt}_{7.5}$ glassy alloy powders and $\mathrm{Sn}$ powders failed to show noticeable response in E-field like other metals, ${ }^{13,20)}$ but could couple with MW and be heated up rapidly to appointed temperatures in $\mathrm{H}$-field. As heating was performed by manipulating the three stubs manually, all heating curves are not smooth. Figure 1(a) and 1(b) show the heating curves of $\mathrm{Ni}_{52.5} \mathrm{Zr}_{15} \mathrm{Nb}_{10} \mathrm{Ti}_{15} \mathrm{Pt}_{7.5}+$ $10 \mathrm{vol} \%$ Sn metallic glassy composite heated up to 783 and $873 \mathrm{~K}$ in H-field. The results are consistent with the reports on the MW heating of metals. ${ }^{21)}$

The chemical compositions of the sintered samples were analyzed. The sample sintered at $783 \mathrm{~K}$ contains 37.1 mass $\%$

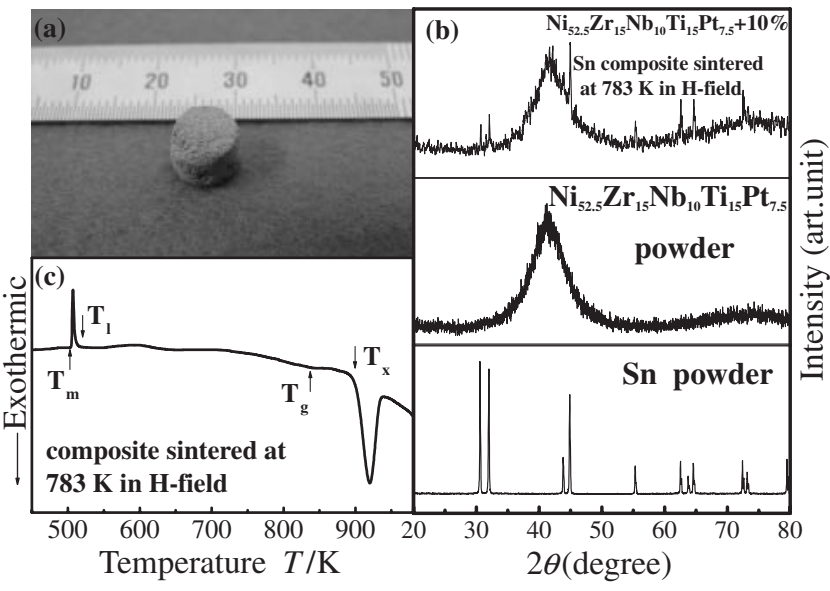

Fig. 2 (a) Outer shape of the sintered Ni-based metallic glass matrix composite containing $10 \mathrm{vol} \% \mathrm{Sn}$ at $783 \mathrm{~K}$. (b) XRD patterns of the sintered specimen at $783 \mathrm{~K}$ and initial $\mathrm{Ni}_{52.5} \mathrm{Zr}_{15} \mathrm{Nb}_{10} \mathrm{Ti}_{15} \mathrm{Pt}_{7.5}$ metallic glassy powder as well as Sn powder. (c) DSC curve of the sintered Nibased metallic glass matrix composite containing $10 \mathrm{vol} \% \mathrm{Sn}$ at $783 \mathrm{~K}$.

$\mathrm{Ni}, 11.3$ mass $\% \mathrm{Nb}, 16.7-16.8$ mass $\%$ Zr, 8.61-8.73 mass\% $\mathrm{Ti}, \quad 17.7$ mass $\% \mathrm{Pt}$ and $8.42-8.51$ mass $\% \mathrm{Sn}$, which is similar to the nominal composition of Ni-based metallic glassy matrix composite $(37.2$ mass $\% \mathrm{Ni}, 11.2$ mass $\% \mathrm{Nb}$, 16.5 mass\% $\mathrm{Zr}, \quad 8.66$ mass $\% \quad \mathrm{Ti}, \quad 17.7$ mass\% $\mathrm{Pt}$ and 8.74 mass $\% \mathrm{Sn}$ ). The outer shape of the sintered Ni-based metallic glass matrix composite containing $10 \mathrm{vol} \% \mathrm{Sn}$ at $783 \mathrm{~K}$ is shown in Fig. 2(a). The sintering process was performed without external pressure, but a compact specimen could be obtained in H-field. Figure 2(b) presents the XRD patterns of the sintered Ni-based metallic glass matrix composite containing $10 \mathrm{vol} \% \mathrm{Sn}$ at $783 \mathrm{~K}$ and initial $\mathrm{Ni}_{52.5} \mathrm{Zr}_{15} \mathrm{Nb}_{10} \mathrm{Ti}_{15} \mathrm{Pt}_{7.5}$ glassy alloy powders as well as $\mathrm{Sn}$ powders. It can be seen that the addition of $\mathrm{Sn}$ particles did not lead to the crystallization of the amorphous phase when it was sintered at $783 \mathrm{~K}$, and its DSC curve shown in Fig. 2(c) presents glass transition and crystallization characteristics as well as the melting process of Sn which further demonstrate that the amorphous phase can be retained by MW sintering. The values of $T_{\mathrm{g}}$ and $T_{\mathrm{x}}$ are determined to be 841 and $904 \mathrm{~K}$, respectively. 


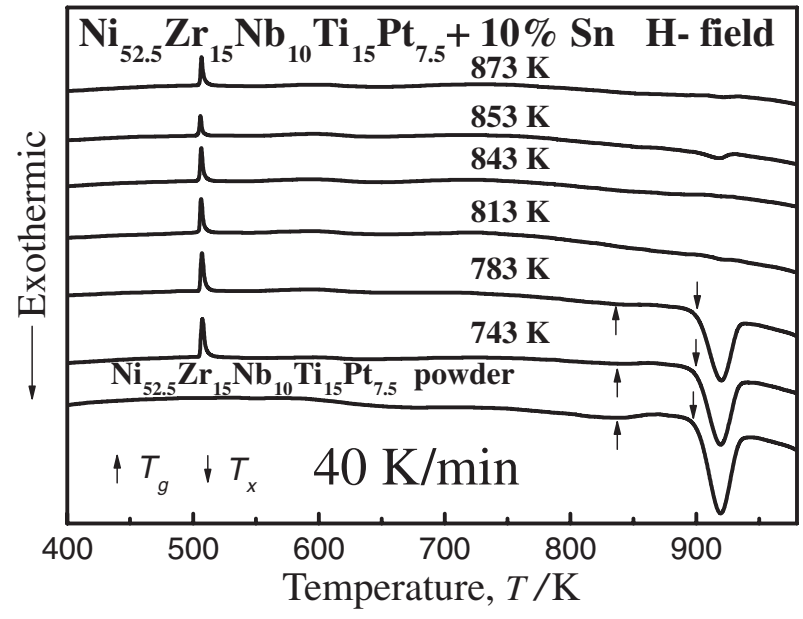

Fig. 3 DSC curves of Ni-based metallic glass matrix composite containing $10 \mathrm{vol} \% \mathrm{Sn}$ with and without MW of heating in $\mathrm{H}$-field at a heating rate of $40 \mathrm{~K} / \mathrm{min}$
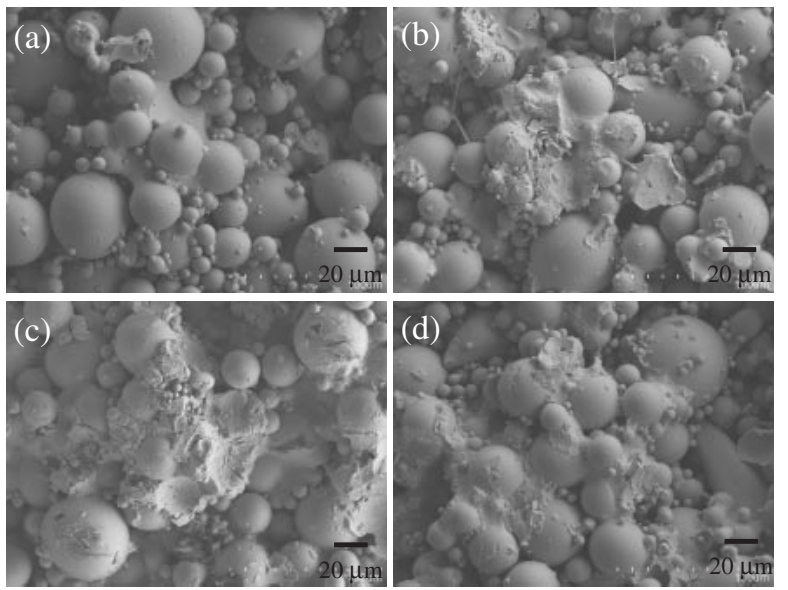

Fig. 4 SEM micrographs of the transverse cross section of the sintered $\mathrm{Ni}_{52.5} \mathrm{Zr}_{15} \mathrm{Nb}_{10} \mathrm{Ti}_{15} \mathrm{Pt}_{7.5}$ metallic glassy specimen containing $10 \mathrm{vol} \% \mathrm{Sn}$ at various temperatures. (a) $783 \mathrm{~K}$, (b) $813 \mathrm{~K}$, (c) $843 \mathrm{~K}$, (d) $873 \mathrm{~K}$.

In order to investigate their thermal stabilities, the DSC curves of the sintering specimens obtained at various sintering temperatures from 743 to $873 \mathrm{~K}$ are presented in Fig. 3. The values of $T_{\mathrm{g}}$ and $T_{\mathrm{x}}$ of the sintered specimens below $783 \mathrm{~K}$ are similar to those obtained for the initial glassy powder. However, the specimens sintered above $813 \mathrm{~K}$ do not show the obvious glass transition and crystallization characteristics, indicating that the crystalline phases with a large volume fraction precipitated in these sintered specimens.

Figure 4 shows SEM micrographs of the transverse cross sections of the sintered Ni-based metallic glass matrix composites containing $10 \mathrm{vol} \% \mathrm{Sn}$ at various temperatures. Adding a relatively small amount of $\mathrm{Sn}$ to $\mathrm{Ni}_{52.5} \mathrm{Zr}_{15} \mathrm{Nb}_{10^{-}}$ $\mathrm{Ti}_{15} \mathrm{Pt}_{7.5}$ metallic glassy alloy powders before MW sintering in $\mathrm{H}$-field has an obvious effect on the quality of the resultant compact specimens. As shown in Fig. 4(a), (b), (c) and (d), Sn particles have all been melted and permeated into the voids and interstices between the $\mathrm{Ni}_{52.5} \mathrm{Zr}_{15} \mathrm{Nb}_{10} \mathrm{Ti}_{15} \mathrm{Pt}_{7.5}$ particles, and then the resulted composites are much denser with a significantly reduced number of voids. Although the crystallization of amorphous phase has occurred in the
Table 1 The sintered densities $\rho$ and relatively densities $\rho / \rho_{0}\left(\rho_{0}\right.$ is theoretical density) of Ni-based metallic glass matrix composites containing $10 \mathrm{vol} \%$ Sn sintered at various temperatures by MW.

\begin{tabular}{ccc}
\hline Sintered temperature $(\mathrm{K})$ & $\rho\left(\mathrm{g} / \mathrm{cm}^{3}\right)$ & $\rho / \rho_{0}(\%)$ \\
\hline 783 & 4.4 & 53 \\
813 & 4.3 & 51 \\
853 & 3.5 & 42 \\
873 & 4.0 & 47 \\
\hline
\end{tabular}

samples sintered above $813 \mathrm{~K}$, there is very little difference in the structures of these specimens sintered at different temperatures. Table 1 lists the measured and relative densities of these sintered specimens at various temperatures. As an external pressure was not applied before and during sintering, densification of only 40-55\% (relatively to the theoretical density of $\mathrm{Ni}_{52.5} \mathrm{Zr}_{15} \mathrm{Nb}_{10} \mathrm{Ti}_{15} \mathrm{Pt}_{7.5}+10 \mathrm{vol} \% \mathrm{Sn}$ metallic powders) was obtained for the sintered bodies at various temperatures. Compared with the density of $\mathrm{Ni}_{52.5} \mathrm{Zr}_{15} \mathrm{Nb}_{10} \mathrm{Ti}_{15} \mathrm{Pt}_{7.5}$ metallic glassy specimen sintered at $843 \mathrm{~K}$ by $\mathrm{MW}^{15)}$ the density was enhanced by Sn addition. With an increase of sintering temperature, the sintered density does not increase, but decreases. Although the sintered densities of this Ni-based metallic glassy matrix composites are low, their compressive strength can be measured and are about 20-50 MPa.

The present results show that the Ni-based metallic glassy powders can be heated well in H-field, and an amorphous phase is retained in the specimens sintered by MW below $783 \mathrm{~K}$. This may be linked with metallic glassy powders and the heating mechanism of MW. MW sintering can provide rapid volumetric heating, which results from the interaction between microwaves and individual particle, and is a very sensitive function of the material being processed and depends on a variety of factors such as size, geometry, mass and dielectric property of the sample. If the ferromagnetic metal particles are heated by MW, magnetic loss and eddy current loss are taken into consideration for the heating mechanism. ${ }^{12)}$ The $M-H$ hysteresis loops of $\mathrm{Ni}_{52.5} \mathrm{Zr}_{15^{-}}$ $\mathrm{Nb}_{10} \mathrm{Ti}_{15} \mathrm{Pt}_{7.5}$ metallic glassy powder and Ni-based metallic glassy matrix composites at ambient temperature, as shown in Fig. 5, reveals that the Ni-based alloy powders exhibit very weak ferromagnetism, and are similar to that of Ni-based alloy ribbon. It has also been found that heating behavior of $\mathrm{Ni}$ particles above Curie point was dependent on the particle size and finer particles could be heated better in a range between 45 and $150 \mu \mathrm{m} .{ }^{13,22)}$ Although the detailed mechanism of the MW sintering metallic powders has not been interpreted clearly and differs with the materials, it might be believed that the mechanism of magnetic loss up to the Curie point and the eddy current loss are responsible for MW heating effect on $\mathrm{Ni}_{52.5} \mathrm{Zr}_{15} \mathrm{Nb}_{10} \mathrm{Ti}_{15} \mathrm{Pt}_{7.5}$ metallic glassy powders with a particle size of no larger than $63 \mu \mathrm{m}$ in $\mathrm{H}-$ field. The retention of amorphous phase in the sintered specimens below $783 \mathrm{~K}$ may attribute mainly to the rapid heating and cooling, short hold time and low sintering temperature in MW sintering. Moreover, Ni-based bulk metallic glass composite containing $10 \mathrm{vol} \% \mathrm{Sn}$ is heated up easily in $\mathrm{H}$-field, which could possibly attributed to different levels of coupling of the samples due to the "MW effect" 


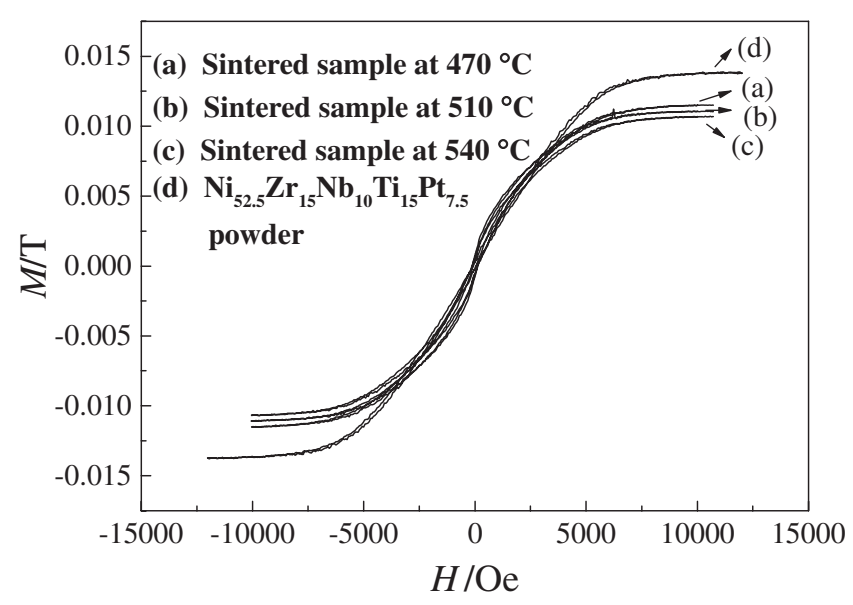

Fig. $5 \quad M-H$ curves of $\mathrm{Ni}_{52.5} \mathrm{Zr}_{15} \mathrm{Nb}_{10} \mathrm{Ti}_{15} \mathrm{Pt}_{7.5}$ metallic glassy powders and Ni-based metallic glassy matrix composites measured at ambient temperature.

which result from locally non-uniform heating in the case of the system consisting of two different components or more. ${ }^{23)}$ The difference in the absorption factors of Ni-based metallic glassy powder and $\mathrm{Sn}$ causes the temperature gradient between the powders to be high which leads to enhanced reaction rates as we observed in Fig. 4. $\mathrm{Ni}_{52.5} \mathrm{Zr}_{15} \mathrm{Nb}_{10} \mathrm{Ti}_{15}$ $\mathrm{Pt}_{7.5}$ metallic glassy powder has a wide supercooled liquid region, but the crystallization occurs when it is sintered at a temperature located in the supercooled liquid region. The possibilities may be considered as follows. Owing to the volumetric heating and radiative loss at surface, the effective bulk temperature of the sintered specimen may be higher than the surface value indicated by pyrometer. If the effective bulk temperature of the sintered specimen is higher than $T_{\mathrm{x}}$, the crystallization will take place for kinetic reasons. The addition of Sn particles may also assist the appearance of crystalline phase in the sintered specimen. As the Ni-based alloy is ferromagnetic, the interaction between MW magnetic field and the ferromagnetic alloy might be considered to stimulate the crystallization. As the heating was completed without the application of an external pressure before and during MW sintering, the density of the sintered body is low. In order to obtain highly compacted specimen by MW processing, Sn particles are added to lead to liquid phase sintering. It is hypothesized that time for diffusion of Sn into Ni-based metallic glass is rather short upon rapid heating in the MW. Therefore, most of the diffusion might have happened at the sintering temperature. As metallic glasses exhibit low viscosity in the supercooled liquid region, MW sintering causes a quick diffusion kinetics of $\mathrm{Sn}$ in $\mathrm{Ni}_{52.5} \mathrm{Zr}_{15} \mathrm{Nb}_{10} \mathrm{Ti}_{15} \mathrm{Pt}_{7.5}$ metallic glass. Sn has a very low melting point and the viscosity of the liquid metal has an Arrhenius dependence on temperature and thus decreases exponentially with temperature above its melting point. ${ }^{21)}$ Its viscosity at the sintering temperature (743-873 K) is low, and thus liquid $\mathrm{Sn}$ can penetrate the fine voids and interstices between the $\mathrm{Ni}_{52.5} \mathrm{Zr}_{15} \mathrm{Nb}_{10} \mathrm{Ti}_{15} \mathrm{Pt}_{7.5}$ particles due to the capillary action, leading to the promotion of shrinkage and densification. The further researches on the effect of Sn on the sintering of Ni-based metallic glassy powders in MW field are being performed.

\section{Conclusions}

MW heating and sintering of Ni-based bulk metallic glass composite containing $10 \mathrm{vol} \% \mathrm{Sn}$ was performed in the separated E- and H-fields. A bulk sintered specimen with retention of an amorphous phase was obtained below $783 \mathrm{~K}$ in H-field, and not heated enough in E-field. It is evident that the MW sintering offers a flexibility to fabricate bulk metallic glasses or composites with complex shape.

\section{Acknowledgements}

The work was supported by Grant-In-Aid "Priority Area on Science and Technology of Microwave-Induced, thermally Non-Equilibrium Reaction No. 18070001 from the Ministry of Education, Culture, Sports, Science and Technology, Japan as well as the Research and Development Project on Advanced Metallic Glasses, Inorganic Materials, and Joining Technology. The authors thank Dr. P. Sharma and C. T. Chang for their help in $M-H$ measurement.

\section{REFERENCES}

1) A. Inoue: Acta Mater. 48 (2000) 279-306.

2) W. L. Johnson: Mater. Res. Soc. Symp. Proc. 554 (1999) 311-323.

3) W. H. Wang, C. Dong and C. H. Shek: Mater. Sci. Eng. R 44 (2004) 45-89.

4) A. Inoue, A. Takeuchi, A. Makino and T. Masumoto: Mater. Trans. JIM 36 (1995) 676-685.

5) B. L. Shen, H. Kimura, A. Inoue, M. Omori and A. Okubo: Mater. Trans. 43 (2002) 1961-1965.

6) Y. Kawamura, H. Kato and A. Inoue: Appl. Phys. Lett. 67 (1995) 2008-2010.

7) G. Q. Xie, W. Zhang, D. V. Louzguine-Luzgin, H. Kimura and A. Inoue: Scr. Mater. 55 (2006) 687-690.

8) R. Roy, D. Agrawal, J. Cheng and S. Gedevanishvili: Nature 399 (1999) 668-670.

9) H. S. Tai and C. J. Jou: J. Hazard. Mater. B 65 (1999) 267-275.

10) J. P. Cheng, D. Agrawal, S. Komarneni, M. Mathis and R. Roy: Mater. Res. Innov. 1 (1997) 44-52.

11) K. Saitou: Scr. Mater. 54 (2006) 875-879.

12) S. Gedevanishvili, D. Agrawal and R. Roy: J. Mater. Sci. Lett. 18 (1999) 665-668.

13) N. Yoshikawa, E. Ishizuka and S. Taniguchi: Mater. Trans. 47 (2006) 898-902.

14) R. M. Anklekar, K. Bauer, D. K. Agrawal and R. Roy: Powder Metall. 48 (2005) 39.

15) N. Yoshikawa, D. V. Louzguine-Luzgin, K. Mashiko, G. Q. Xie, M. Sato, A. Inoue and S. Taniguchi: Mater. Trans. 48 (2007) 632-634.

16) T. Kimura, H. Takizawa, K. Ueda and T. Endo: Proc. Int. Conf. Microwave Chemistry, (Institute National Polytechnique de Toulouse, Toulouse, France, 2000) p. 335.

17) R. Roy, R. Peelamedu, C. Grimes, J. Cheng and D. Agrawal: J. Mater. Res. 17 (2002) 3008-3011.

18) D. V. Louzguine-Luzgin, T. Shimada and A. Inoue: Intermetallics 13 (2005) 1166-1171.

19) G. Q. Xie, D. V. Louzguine-Luzgin, H. Kimura and A. Inoue: Appl. Phys. Lett. 90 (2007) 241902-1-3.

20) R. Roy, R. Peelamedu, L. Hurtt, J. Cheng and D. Agrawal: Mater. Res. Innov. 6 (2002) 128-140.

21) W. D. Kingery and M. D. Narasimhan: J. Appl. Phys. 30 (1959) 307-310.

22) J. L. Wallace: IEEE Trans. Magnetics. 29 (1993) 4029-4215.

23) R. Roy, D. Agrawal and J. P. Cheng: Microw. Theor. Appl. Mater. Proc. V, Ceram. T. III (2000) P. 459. 